\title{
Kil İçeriği Yüksek Aslantaş Baraj Gölü Çökelti Malzemesinin Seramik Üretiminde Kullanılabilirliğinin Araştırılması
}

\author{
Nergis KILINÇ MIRDALI"1 ${ }^{*}$, Mustafa DADAY ${ }^{2}$, Mine TAYKURT DADAY ${ }^{3}$ \\ ${ }^{I}$ Çukurova Üniversitesi, Güzel Sanatlar Fakültesi, Seramik Bölümü, Adana \\ ${ }^{2}$ Eskişehir Teknik Üniversitesi, Mühendislik Fakültesi, Malzeme Bilimi ve Mühendisliği Bölümü, \\ Eskişehir \\ ${ }^{3}$ Adana Alparslan Türkeş Bilim ve Teknoloji Üniversitesi, Mühendislik Fakültesi, Malzeme \\ Mühendisliği Bölümü, Adana
}

Geliş tarihi: 15.01.2019 Kabul tarihi: 27.03.2019

Öz

Aslantaş Baraj Gölü, Karatepe-Aslantaş Milli Parkı ve Açık Hava Müzesi'ne komşu olan kıyılara sahip bir baraj gölüdür. Bu bölgenin tarihi değeri düşünüldüğünde, çökelen hammaddenin tanınması ve seramiklerde kullanımının araştırılması önem arz etmektedir. Çökelti malzemesinin tane boyutu ve dağılımı, lazer parçacık boyutu ve dağılımı ölçme cihazı ile ölçülmüştür. Hammaddenin kimyasal ve mineralojik analizi X-1şını floresans (XRF) ve X-1şını kırınımı (XRD) metodu ile yapılmıştır. Numunenin ısıl davranışı termogravimetrik/diferansiyel taramalı analiz cihazı (TGA/DTA) ve optik dilatometre (ODHTM) ile tespit edilmiştir. Bünye numuneleri yarı-yaş yöntemle (plastik şekillendirme) hazırlanmış, astarlar renklendirilerek farklı kompozisyonlardaki seramik çamurlarından üretilen bünyeler üzerine uygulanmıştır. Numuneler $800,900,1000,1100$ ve $1200{ }^{\circ} \mathrm{C}$ 'de firınlanmış ve tüm bünyelerin boyutsal küçülme değerleri ölçülmüştür. Pişirimin ardından renk değerleri CIE-L*a*b* yöntemiyle tespit edilmiştir. Alınan sonuçların ışı̆̆ında, hammaddenin, seramik astar ve bünye olarak kullanılabileceği fakat içerisindeki kalsiyum karbonat miktarının yüksekliği nedeniyle ince bir katman olarak uygulanan astarlarda daha iyi sonuçlar elde edileceği saptanmıştır.

Anahtar Kelimeler: Karatepe, Seramik bünye, Astar, Karakterizasyon, Renk

\section{Investigation of Usage Possibility of High Sedimentary Clay Content in Raw Material from Aslantas Dam Lake for Ceramic Production}

\begin{abstract}
Aslantaş Dam Lake is a dam with a shore adjacent to Karatepe-Aslantaş Open-Air and Closed Museum. Considering the historical value of this region, it is important to identify the raw material that has been precipitated and to investigate its use in ceramics. Particle size and distribution was defined with laser particle sizer of sedimentary clay material. The chemical and mineralogical composition of raw material
\end{abstract}

*Sorumlu yazar (Corresponding author): Nergis KILINÇ MİRDALI, nergismirdali@gmail.com 
was determined by X-ray fluorescence (XRF) and X-ray diffraction (XRD) methods. Thermal behaviour of sample was studied by Thermogravimetric/Differential Scanning Analyzer (TGA-DTA) and Optical Dilatometer (ODHTM). The body samples were prepared by semi-dry (plastic shaping), the engobes were colored and applied on bodies made of ceramic muds in different compositions. The samples were fired at $800,900,1000,1100$ and $1200{ }^{\circ} \mathrm{C}$ and shrinkage values were measured for each bodies. The color properties obtained after firing was defined as CIE-L*a*b* parameters. In the light of these results, it was determined that the raw material could be used as a ceramic body and an engobe, but because of the high amount of calcium carbonate, it was found that the engobe applied as a thin layer would have better results.

Keywords: Karatepe, Ceramic body, Engobe, Characterization, Color

\section{GíRiş}

Aslantaş Baraj Gölü, Karatepe-Aslantaş Milli parkı sınırları içerisinde ve Ceyhan Nehri üzerinde $37^{\circ} 16^{\prime} 19^{\prime \prime}$ Kuzey ve $36^{\circ} 16^{\prime} 21^{\prime \prime}$ Doğu enlemleri üzerinde yer almaktadır. Denizden yüksekliği $160 \mathrm{~m}$, yüzeyi $49 \mathrm{~km}^{2}$ ve en derin yeri $78 \mathrm{~m}$ 'dir. Bölge Şekil 1'de haritada gösterilmektedir.

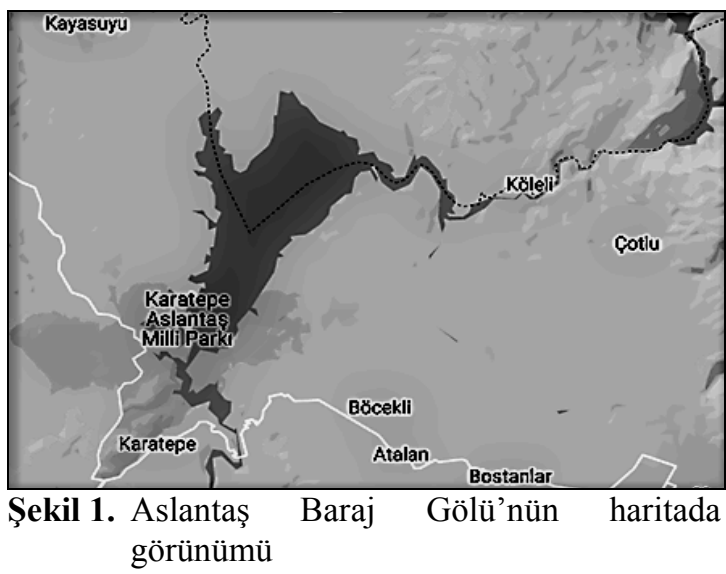

$\mathrm{Bu}$ bölgenin tarihi Geç Hitit Dönemi’ne, yani MÖ 8. yy.'a kadar dayanmaktadır. Barındırdığı tarih 1946 yılından bu yana gün yüzüne çıkarılmakta ve eserler Türkiye'nin ilk açık hava müzesi olan Karatepe Aslantaş müzesinde sergilenmektedir [1]. Bazaltik kayaçlardan yapılmış olan eserlerin değerinin paha biçilmez oluşu, akıllara bölgeye ait taşa ve toprağa dayalı sanat eserlerinin üretiminin gerekliliğini getirmektedir. Bu sebepten ötürü, Aslantaş Baraj Gölü'nün kıyısına çökelen kil içeriği yüksek hammaddeden hazırlanan bünye ve astarlar seramik özellikleri açısından incelenmiştir.
$\mathrm{Bu}$ bölgedeki kayaçların ve bölgeden çıkartılan tarihi eserlerin bazaltik yapısı oluşan çökelti malzemelerin bazalt bozulumları sonucu oluştuğu fikrini akla getirmiştir. Bazalt, içerisinde \%45-52 silika içeren volkanik bir kayaçtır ve esas olarak içerisinde kalsitik plajiyoklas, klinoproksen ve olivin mineralleri bulunur. $\mathrm{Bu}$ baskın mineraller değişken hava şartları sayesinde kolaylıkla ayrışırlar [2]. Volkanik taşlar yüksek sıcaklıklarda oluşurlar ve suyun bulunduğu ortamlarda düşük sıcaklıklarda bile kararlı değildirler [3]. Bilindiği üzere kil mineralleri tabakalı yapısı ve buna bağlı olarak da plastiklik özelliği nedeniyle özsüz hammaddeleri bir arada tutarak seramik ürünlerin şekillendirilmesine olanak veren temel seramik hammaddesidir. Ancak bütün kil mineralleri aynı içeriğe sahip değildir. Seramik ürünlerin yüzeyini kaplayan astarın yapımında doğal killerle çeşitli özelliklerde ve geniş renk yelpazesine sahip astarlar üretilebilir. Ayrıca astarların renklendirilmesinde pigment veya oksitler de kullanılabilir [4]. Kil mineralleri kaolinit, illit, smektit veya klorit karakterli olabileceği gibi, karışık yapıda da olabilmektedir [5]. Çalışma alanında kil dışında kalsiyum karbonat $\left(\mathrm{CaCO}_{3}\right)$ içeren aragonit, kalsit ve dolomit mineralleri de yer almaktadır. Karbonat içermeyen killer oksijenli firın atmosferinde pişirildiklerinde kırmızımsı kahverengiye ve indirgeyici atmosferde koyu griye dönüşürler [6-8]. Karbonatça zengin killer aynı pişirim koşullarında fırınlandıklarında renkleri krem rengi veya kahverengimsi olur. Karbonatların seramiklerin pişirilmesi sırasındaki etkileri birçok araştırmacı tarafından araştırma konusu olmuştur [9-15]. Kalsit ve aragonit, aynı kimyasal formülde $\left(\mathrm{CaCO}_{3}\right)$ olup, atomları farklı yapıda dizilir. Her iki mineral de kalsiyum karbonatın iki ayrı kristal 
şeklidir ve teorik olarak $\% 56 \mathrm{CaO}$ ve $\% 44 \mathrm{CO}_{2}$ içerir [16]. Özellikle kaba taneli kalsit $(>1 \mathrm{~mm})$ pişirim sırasında tamamıyla kalsiyum silikata dönüşmeyebilir. Hidratasyon ve karbürüzasyon bünyenin hacimce genleşmesine ve zararlı kireç patlaklarının oluşmasına neden olur [17]. Seramik astarlar deri sertliğindeki seramik ürün yüzeyine dekoratif ve teknik amaçla tek başına uygulanabileceği gibi, sır altına da uygulanabilir. Başka bir deyişle seramik astarlar uygulandıkları bünyenin rengini kapatabildikleri gibi, onlara geçirimsizlik ve opaklık kazandırarak yüzeydeki hataları gizlemek amaçlı da kullanılabilir [18-20]. Ancak seramik bünyelerde ağırlıkça \%10'dan fazla kalsiyum karbonat $\left(\mathrm{CaCO}_{3}\right)$ var ise hatalara yol açar.

$\mathrm{Bu}$ çalışmanın amacı, Aslantaş Baraj Gölü’nde çökelmiş kil içeriği yüksek olan hammaddenin, seramik üretimindeki teknolojik potansiyelini incelemektir.

\section{MATERYAL VE YÖNTEM}

Hammadde, göl yatağının su kenarına yakın kısmından yaklaşık $5 \mathrm{~cm}$ kalınlıkta bir tabaka olarak yüzeyden kazınarak alınmıştır. Alçı tezgâh üzerinde suyu çektirilerek 5 gün oda koşullarında kurutulmuştur. El ile ayrılabilen organik atıklar (ağaç dalları ve yaprakları, otsu bitkiler vs.) ayıklanmıştır. Süspansiyonlar 1 gün bekletilip özsüz iri taneli kısmın dibe çökmesi sağlanmış ve $1 \mathrm{~mm}$ elek açıklığına sahip elekle kaba taneler ayrılmıştır.

\subsection{Deney Tabletlerinin Hazırlanması}

Bünyeleri yarı-yaş şekillendirebilmek için elenen süspansiyon, alçı plaka üzerine dökülerek fazla suyu çektirilmiştir. Plastik çamur yaklaşık \%30 şekillendirme suyuna ulaştığında, $55 \mathrm{~mm}$ x $55 \mathrm{~mm}$ x $10 \mathrm{~mm}$ boyutlarında kesilerek yüzeylerine küçülme ölçümü yapabilmek için kumpas yardımı ile iz bırakılmıştır. Tabletler önce 2 gün oda koşullarında, ardından $110{ }^{\circ} \mathrm{C}$ 'de etüvde 24 saat kurutulmuştur. Pişirimler elektrikli firında, 800 , 900, 1000, 1100 ve $1200{ }^{\circ} \mathrm{C}$ sicaklikta, $5{ }^{\circ} \mathrm{C} / \mathrm{dk}$ isıtma hızıyla ve $20 \mathrm{dk}$ tepe sicaklığında bekletilerek yapılmıştır.

\subsection{Astarların Hazırlanması}

Astarlar; yaklaşık $1500 \mathrm{~g} / \mathrm{lt}$ litre ağırlığında olacak şekilde katkısız (H.M.) ve içerisine \%10-15-20 kobalt klorür, nikel oksit ve bakır oksit ilave edilerek hazırlanmıştır. Ardından, hazırlanan süspansiyonlar kaolinitik karakterli ve demir oksit içeriği düşük beyaz döküm çamurundan (D.Ç.), illitik karakterli ve demir oksit içeriği yüksek kırmızı torna çamurundan (T.Ç.) ve şamotlu çamurdan (Ş.Ç.) üretilmiş, deri sertliğindeki bünyeler üzerine ince bir tabaka halinde firça ile sürülerek uygulanmıştır. Astarlanmış numuneler, elektrikli firında 900,1000 ve $1100{ }^{\circ} \mathrm{C}$ sicaklıkta, $5{ }^{\circ} \mathrm{C} / \mathrm{dk}$ isıtma hızıyla ve $20 \mathrm{dk}$ tepe sıcaklığında bekleme verilerek pişirilmiştir.

\subsection{Karakterizasyon}

Hammaddenin tane boyutu ve dağılımı, Malvern marka MS 3000 model (Ölçüm aralığı: 0,01-3500 $\mu \mathrm{m})$ lazer parçacık boyutu ve dağılımı ölçme cihazı ile ölçülmüştür.

Kimyasal analiz, toz numune üzerine Rigaku marka ZSX Primus II X-1şınları flouresans spektrometresi (XRF) ile yarı kantitatif bir şekilde (Ölçüm aralığı: Bor'dan Uranyum'a kadar) ve mineralojik analiz, Rigaku marka Miniflex 600 model X-ışınları kırınımı (XRD) cihazı (Tarama hızı $=2{ }^{\circ} \mathrm{C} / \mathrm{dk}$, Tarama açısı $(2 \Theta)=10-70$, Enerji: $40 \mathrm{kV}$ ve $30 \mathrm{~mA}, \mathrm{Cu}=\mathrm{K} \alpha$ ) ile yapılmıştır.

Is1 analiz, Hitachi marka STA7300 model Termogravimetrik/Diferansiyel taramalı analiz cihazı (TGA/DTA) ile (Maksimum pişirim sıcaklığı: $1200{ }^{\circ} \mathrm{C}$ ) ve Misura marka 3.32 ODHTHSM 1600/80 model optik dilatometre ile (Maksimum pişirim sıcaklığı: $1200{ }^{\circ} \mathrm{C}$ ) tespit edilmiştir.

$\%$ Nem miktarı Eşitlik 1 kullanılarak hesaplanmıştır.

$\% \mathrm{Nem}=\left[\left(\mathrm{m}_{0}-\mathrm{m}_{1}\right) / \mathrm{m}_{0}\right]^{*} 100$

Burada; Nem miktarı (\%), mo: Yaş ağırlık (g) ve $\mathrm{m}_{1}$ : Kuru ağırlık (g)'tır. 
Pişirimler Protherm marka PLS 160 model elektrikli fırın ile gerçekleştirilmiştir. S1caklığa göre ateş kaybı değişimi değerleri Eşitlik 2 kullanılarak hesaplanmıştır.

A. $K=\left[\left(m_{1}-m_{2}\right) / m_{1}\right] * 100$

Burada; A.K: Ateş kaybı (\%), $\mathrm{m}_{1}$ : Kuru ağırlık (g) ve $\mathrm{m}_{2}$ : Pişmiş ağırlık ( $\mathrm{g}$ )'tır. Boyutsal değişimler Eşitlik 3 ve Eşitlik 4 kullanılarak hesaplanmıştır.

$\mathrm{K} . \mathrm{K}=\left[\left(\mathrm{h}_{0}-\mathrm{h}_{1}\right) / \mathrm{h}_{0}\right] * 100$

$\mathrm{T} . \mathrm{K}=\left[\left(\mathrm{h}_{0}-\mathrm{h}_{2}\right) / \mathrm{h}_{0}\right] * 100$

Burada; K.K: Kuru küçülme (\%), T.K: Toplam küçülme $(\%), h_{0}$ : Yaş tablet üzerindeki iz boyutu $(\mathrm{mm}), \mathrm{h}_{1}$ : Kuru tablet üzerindeki iz boyutu $(\mathrm{mm})$ ve $\mathrm{h}_{2}$ : Pişmiş tablet üzerindeki iz boyutu $(\mathrm{mm})$ 'dur. Renk ölçümleri Konica Minolta marka 3600D model spektrofotometre ile CIE-L*a*b* sisteminde tespit edilmiştir. $\mathrm{Bu}$ analizde L* açıkl1-koyuluk, a* kırmızılık-yeşillik ve $\mathrm{b}^{*}$ sarıl1k-maviliktir.

\section{BULGULAR VE TARTIŞMALAR}

\subsection{Hammadde Karakterizasyonu}

\subsubsection{Tane Boyut Analizi}

Bünyede ve astarda kullanılan hammaddenin tane boyut ve dağılımı Şekil 2'de verilmiştir. Yapılan analizde, $\quad \mathrm{d}_{10}=1,44 \mu \mathrm{m}, \quad \mathrm{d}_{50}=8,04 \mu \mathrm{m} \quad$ ve $\mathrm{d}_{90}=30,00 \mu \mathrm{m}$ olduğu, en büyük tanelerin ise $51,80 \mu \mathrm{m}$ olduğu tespit edilmiştir. $\mathrm{Bu}$ veriler, tanelerin düzgün dağıldığını ve hem bünye hem de astar üretimi için öğütme gerektirmeden kullanılabileceğini göstermektedir.

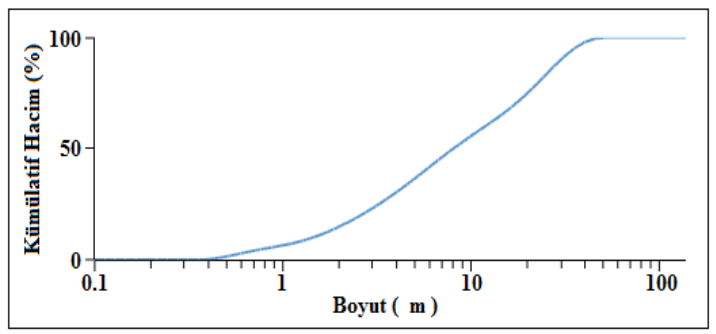

Şekil 2. Hammaddenin tane boyut analizi

\subsubsection{X-Işını Flouresans Spektrometresi Analizi (XRF)}

Hammaddenin kimyasal analiz sonuçları Çizelge 1'de sunulmuştur. Hammaddenin ana bileşenlerinin $\mathrm{SiO}_{2}, \quad \mathrm{Al}_{2} \mathrm{O}_{3}$ ve $\mathrm{CaO}$ olduğu görülmektedir. Silika, kristalin yapıda tetrahedraları oluşturması ve cam içerisinde cam yapıc1 oksit olması nedeniyle miktarının $\% 50$ ve üzeri olması istenmektedir. Kristal yapıda görev aldığ 1 ve oktahedraları oluşturduğu bilinen $\mathrm{Al}_{2} \mathrm{O}_{3}$ değerinin \%10'un üzerinde olması, hammaddeyi bünye ve astar için uygun kılmaktadır. Özellikle bünyenin yığınsal (bulk) yapısı nedeniyle olumsuz yönde etkilenebileceği en önemli bileşen, $\mathrm{CaO}$ olarak düşünülebilir. $\mathrm{CaO}$, hammaddenin içerisinde $\mathrm{CaCO}_{3}$ formunda olduğunda ve miktarının \%10'un üzerinde olması durumunda pişirimin ardından kireç patlağı denilen hataya yol açmaktadır. Hammaddenin içerisindeki $\mathrm{Fe}_{2} \mathrm{O}_{3}$, yükseltgen firın atmosferinde ve sicaklığın artmasıyla, özellikle bünyede rengin açıtan koyuya kahverenginin farklı tonlarına dönmesine neden olmaktadir.

Çizelge 1. Hammaddenin kimyasal analizi

\begin{tabular}{|c|c|}
\hline Oksitler & Miktar (\%) \\
\hline $\mathrm{SiO}_{2}$ & 37,24 \\
\hline $\mathrm{Al}_{2} \mathrm{O}_{3}$ & 11,64 \\
\hline $\mathrm{CaO}$ & 40,18 \\
\hline $\mathrm{MgO}$ & 3,78 \\
\hline $\mathrm{Na}_{2} \mathrm{O}$ & 0,36 \\
\hline $\mathrm{K}_{2} \mathrm{O}$ & 1,31 \\
\hline $\mathrm{Fe}_{2} \mathrm{O}_{3}$ & 4,11 \\
\hline $\mathrm{TiO}_{2}$ & 0,76 \\
\hline $\mathrm{Diğer}$ & 0,63 \\
\hline
\end{tabular}

\subsubsection{X-Işını Kırınım Analizi (XRD)}

Pişirim öncesi hammaddenin içerisindeki mineraller, pişirim sonrasındaki tüm kimyasal ve fiziksel özellikler için önem arz etmektedirler. Şekil 3'de hammaddenin X-1şını kırınım deseni gösterilmiştir. Hammadde içerisinde kil minerali olarak kaolinit ve illit bulunmaktadırlar. Kil mineralleri, şekillendirme aşamasında plastikliği ve mukavemeti sağlar ve sıcaklık arttıkça bozunarak yüksek sıcaklık fazlarını oluştururlar. 
Aragonit ve kalsit, kalsiyumun karbonat kaynağı, dolomit ise kalsiyum ve magnezyumun kaynağı olarak bulunmaktadır. Toprak alkali grubuna ait elementleri içeren bu mineraller pişirim sıcaklığını düşürmede fayda sağlamaktadırlar. Kuru mukavemeti arttırıcı ve pişirim sırasında camsı fazı oluşturacak olan $\mathrm{SiO}_{2}$, kuvars minerali olarak tespit edilmiştir.

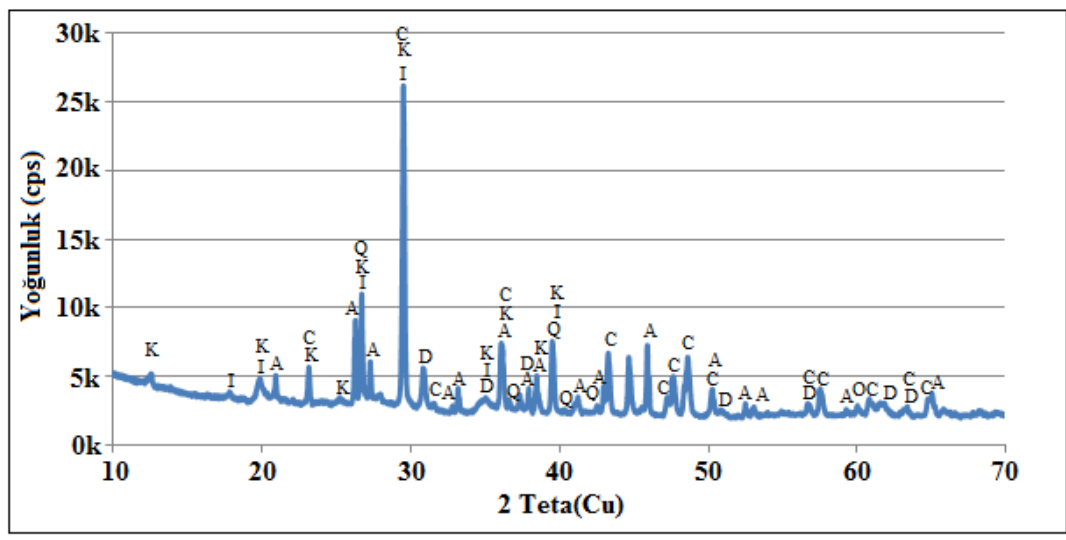

Şekil 3. Hammaddenin X-ışını kırınımı (K: Kaolinit, I: İllit, A: Aragonit, C: Kalsit, D: Dolomit ve Q: Kuvars)

\subsubsection{Isıl Analiz}

\subsubsection{Termogravimetrik/Diferansiyel Taramalı Analiz (TG/DTA)}

Isıl davranışın tespit edilmesinde kullanılan TG/DTA analizine ait sonuç Şekil 4'de verilmiştir. Oda sıcaklığından $100{ }^{\circ} C^{\prime}$ ye kadar olan \%3,8 kütle azalımı fiziksel suyun uzaklaşması, $325-550{ }^{\circ} \mathrm{C}$ arası $\% 4,4$ kütle azalımı kil bozunumu, 550-760 ${ }^{\circ} \mathrm{C}$ arası \%21,8 kütle azalımı karbonat bozunumu olarak ve oda sicaklığından $1200{ }^{\circ} \mathrm{C}$ sicaklığa kadar toplamda kaybedilen kütle $\% 31,1$ olarak tespit edilmiştir. $1150{ }^{\circ} \mathrm{C}$ 'nin üzerinde camsı fazın oluşmaya başladı̆̆ı görülmektedir.

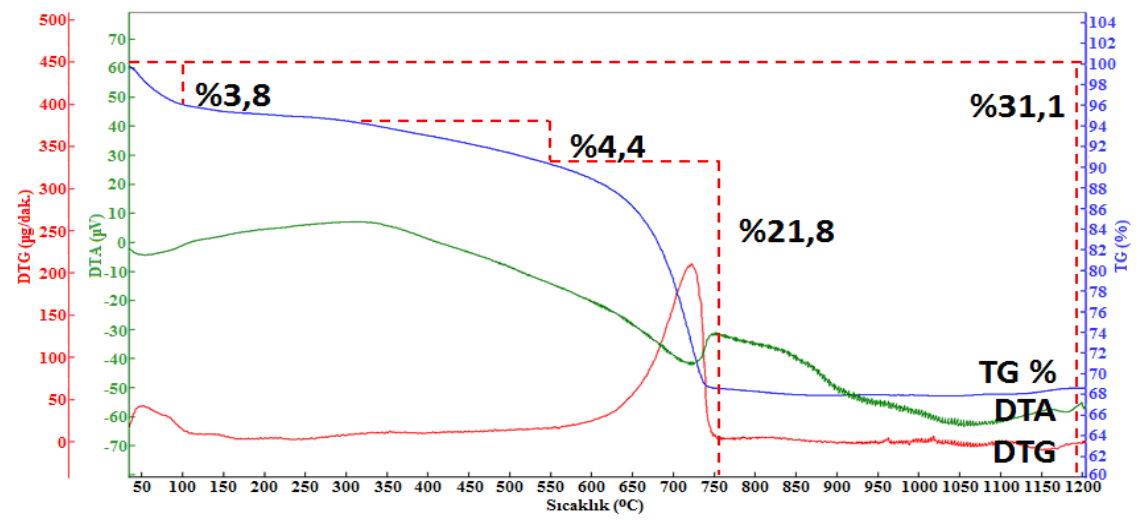

Şekil 4. Hammaddenin TG/DTA analizi

\subsubsection{Optik Dilatometre (ODHT-HSM)}

Seramik pişirim sıcaklığını belirleyebilmek için yapılan dilatometrik analiz sonucu, Şekil 5'de sunulmuştur. Yapılan analiz, hammaddenin sinterlenmesinin en hızlı olduğu sıcaklığın $\sim 1190{ }^{\circ} \mathrm{C}$ olduğu ve pişirim sicaklığının bu sıcaklık çevresinde olabileceği konusunda fikir vermektedir. 


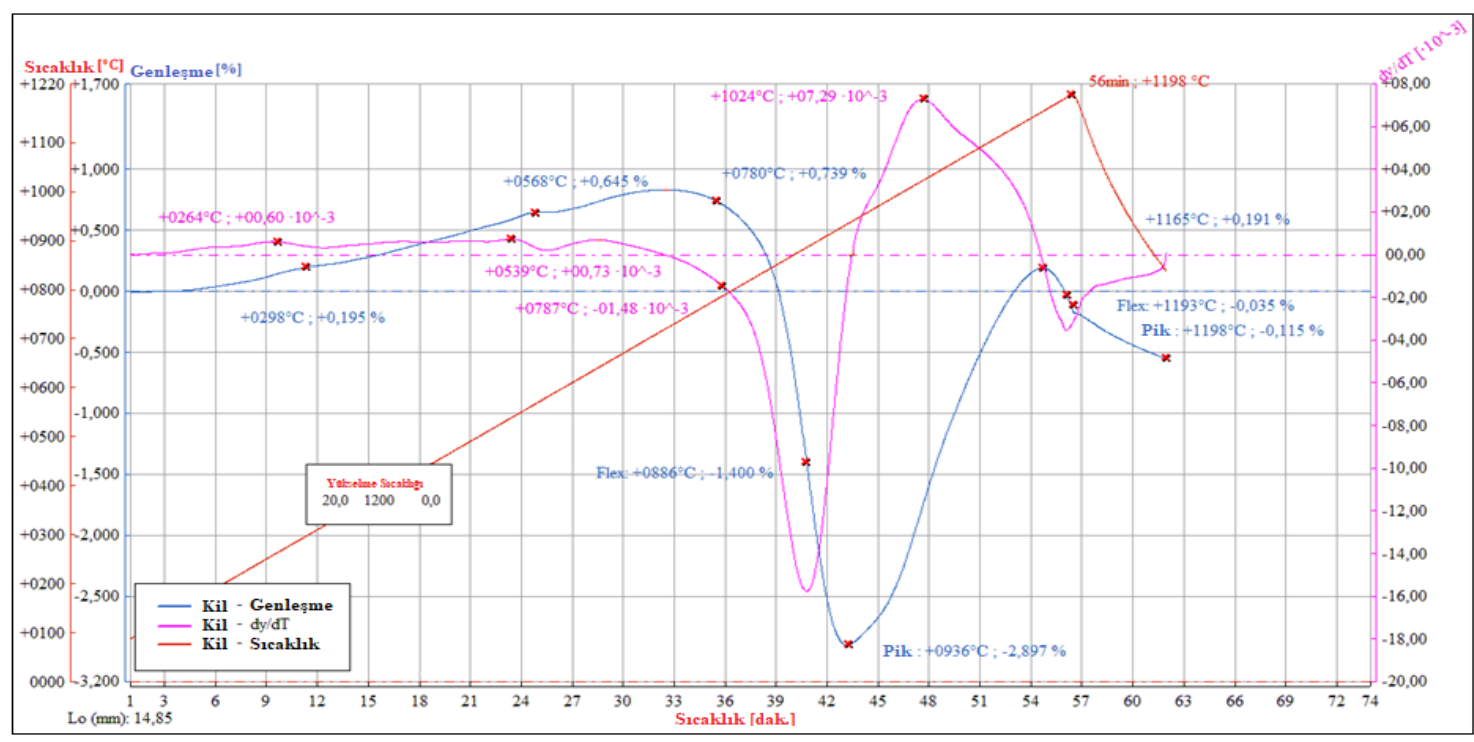

Şekil 5. Hammaddenin optik dilatometre analizi

\subsection{Fiziksel Özellikler}

\subsubsection{Genel Fiziksel Özellikler}

Bünyelerin kuruma davranışları Şekil 6'da gösterilmektedir. Oda sicaklığında kurutulan numunelerden uzaklaşan nem miktarı \%27,43, $110{ }^{\circ} \mathrm{C}$ 'de etüvde kurutulan numunelerden uzaklaşan ise \%30,31 olarak bulunmuştur. Aradaki fark \%2,78'dir ve bu fark oda sıcaklığında şekillendirme suyunun tamamının bünyeden uzaklaşmadığını göstermektedir. Bu nedenle özellikle pişirimin ilk aşamasında numunelerin zarar görme riskleri vardır. Pişirim öncesi kalıntı rutubetin bünyeden tamamen uzaklaştırılması için etüvde kurutma yapılması gerekmektedir.

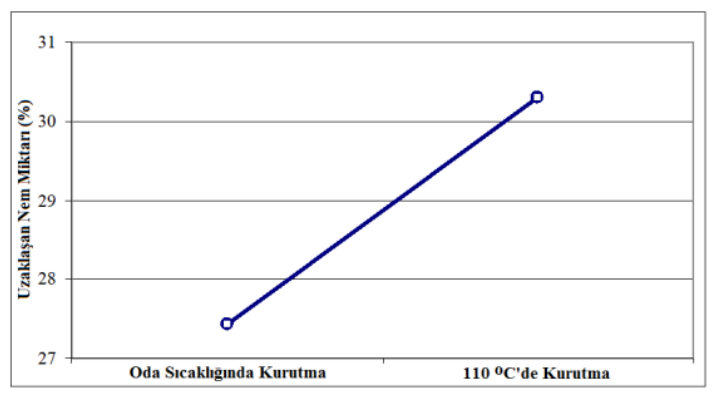

Şekil 6. Bünyelerin kurutma davranışları
Şekil 7'de bünyelerin sıcaklığa karşı kütle kaybı eğrisi verilmektedir. En düşük sıcaklıkta \%15,14 olarak tespit edilen ateş kaybı, sıcaklık arttıkça artmış, $1000{ }^{\circ} \mathrm{C}^{\prime}$ ye gelindiğinde tüm bozunma reaksiyonları tamamlanmış ve $1200{ }^{\circ} \mathrm{C}^{\prime}$ ye kadar $\% 27,65$ seviyesinde sabitlenmiştir.

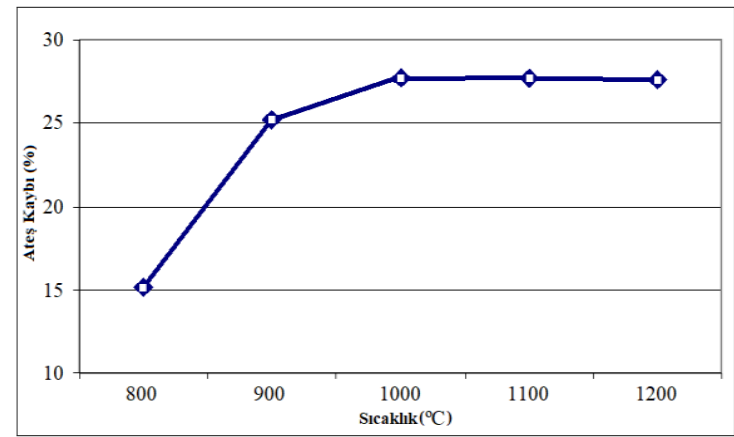

Şekil 7. Bünyelerin ateş kayıpları

Seramik bünyelerde, normal koşullarda, sıcaklık arttıkça lineer küçülmenin de artması beklenmektedir. Şekil 8'de gösterilmiş olan pişirim sonrası toplam küçülme eğrisine bakıldığında, $800{ }^{\circ} \mathrm{C}^{\prime} \mathrm{de} \% 9,44$ olan küçülme değeri, $900{ }^{\circ} \mathrm{C}$ 'de $\% 11,02$ 'ye yükselerek beklenen davranışı sergilemiştir. Fakat 1000 ve $1100{ }^{\circ} \mathrm{C}$ 'de küçülme değerleri \%9,00'a düşmüştür. $\mathrm{Bu}$ durum 900-1200 ${ }^{\circ} \mathrm{C}$ aralığında bünyenin içerisinde kristal 
oluşumu olabileceğini akla getirmektedir [21]. Sıcaklığa bağlı faz gelişimi bu çalışmanın kapsamı dışındadır. Son pişirim sıcaklığında $\left(1200{ }^{\circ} \mathrm{C}\right)$ toplam küçülme değeri \%9,88'dir.

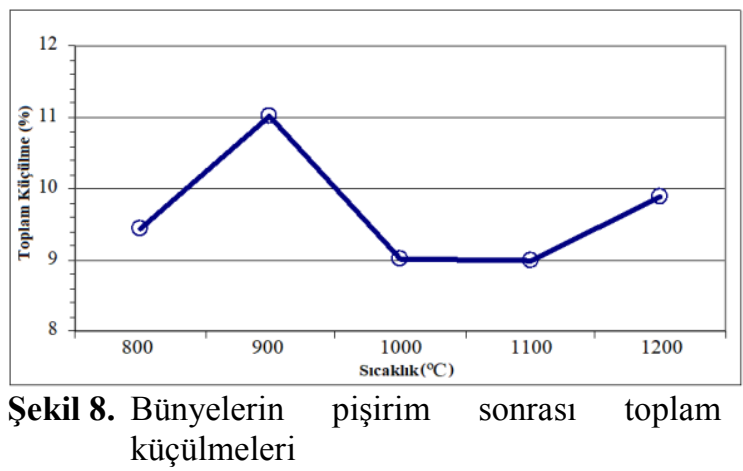

\subsubsection{Renk Özellikleri}

Bünye ve astarların renklerini karşılaştırabilmek için, Karatepe-Aslantaş Açık Hava Müzesi tarihi eserlerinin fotoğraflarından renk değerleri alınmış ve veriler CIE-L*a*b* renk sisteminde değerlendirilmiştir. Şekil 9'da tarihi eserlerin fotoğraflarındaki noktalar ve Şekil 10'da bu verilerin sayısal değerleri yıldız (*) işaretiyle gösterilmektedir.

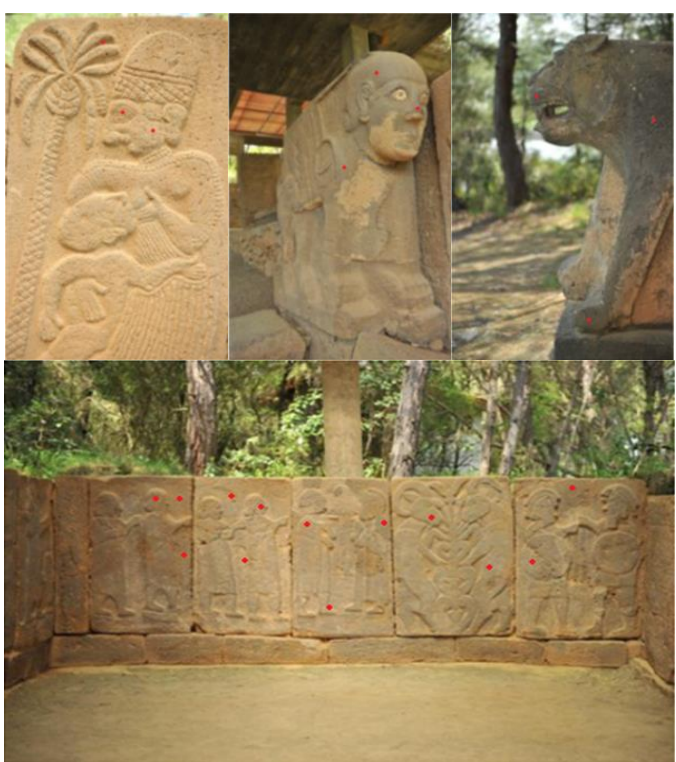

Şekil 9. Tarihi eserlerin fotoğraflarında [1] renk değeri belirlenen noktalar

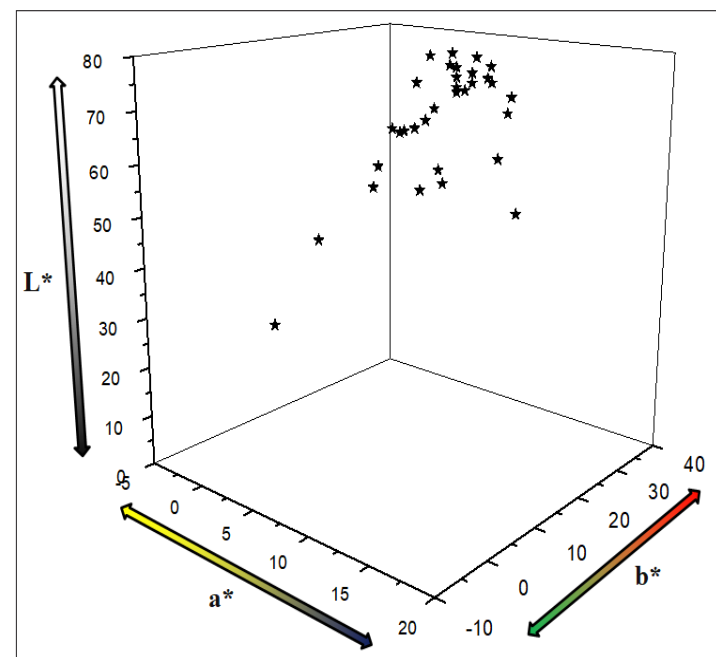

Şekil 10. Tarihi eserler (*) üzerinden alınan renklerin $\mathrm{L}^{*} \mathrm{a}^{*} \mathrm{~b}^{*}$ sisteminde gösterimi

Hem bünyelerin hem de astarların tüm denemeleri için renkleri Çizelge 2'de ve yapılan renk analizi Şekil 11'de verilmektedir. Analizden anlaşılmaktadır ki, tarihi eserlerin renk değerlerine en yakın olan renkler, bünyelerin farklı sıcaklıklardaki pişiriminden elde edilen renklerdir. Şekil 11'de bu verilerin sayısal değerleri; tarihi eserler yıldız $(*)$, bünyeler üçgen $(\Delta)$ ve astarlar çember $(\circ)$ işaretleriyle gösterilmektedir.

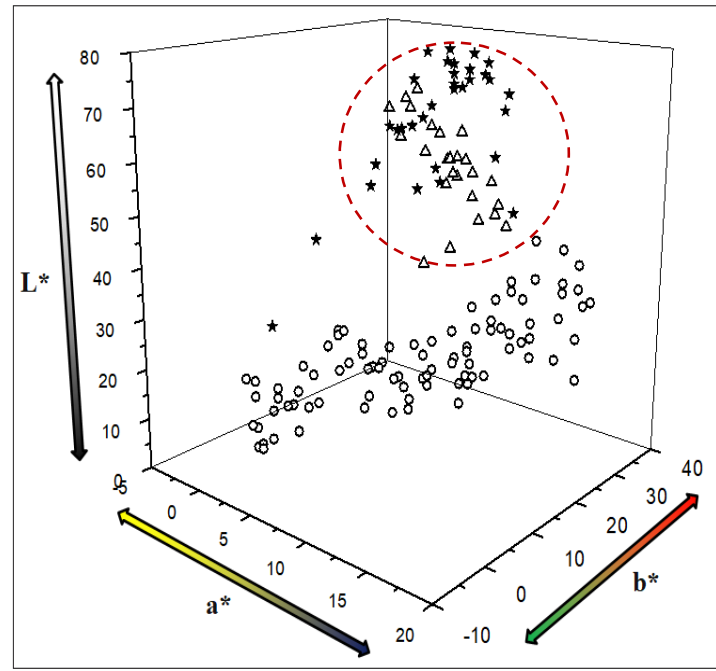

Şekil 11. Tarihi eserler $(*)$, bünyeler $(\Delta)$ ve astarlardan $(\circ)$ alınan renklerin $L^{*} a^{*} b^{*}$ sisteminde gösterimi 
Çizelge 2. Tüm denemeler için renkler

\begin{tabular}{|c|c|c|c|c|}
\hline $\begin{array}{c}\text { Sicaklik } \\
\left({ }^{\circ} \mathrm{C}\right)\end{array}$ & Bünye & Katkı & $\begin{array}{c}\text { Katk1 Oranı } \\
(\%)\end{array}$ & Renk \\
\hline 800 & H.M. & - & - & \\
\hline 900 & H.M. & - & - & \\
\hline 900 & D.Ç. & - & - & \\
\hline 900 & S.Ç. & - & - & \\
\hline 900 & T.Ç. & - & - & \\
\hline 900 & D.Ç. & Kobalt Klorür & 10 & \\
\hline 900 & S.Ç. & Kobalt Klorür & 10 & \\
\hline 900 & T.Ç. & Kobalt Klorür & 10 & \\
\hline 900 & D.Ç. & Kobalt Klorür & 15 & \\
\hline 900 & S.Ç. & Kobalt Klorür & 15 & \\
\hline 900 & T.Ç. & Kobalt Klorür & 15 & \\
\hline 900 & D.Ç. & Kobalt Klorür & 20 & \\
\hline 900 & S.Ç. & Kobalt Klorür & 20 & \\
\hline 900 & T.Ç. & Kobalt Klorür & 20 & \\
\hline 900 & D.Ç. & Nikel Oksit & 10 & \\
\hline 900 & S.Ç. & Nikel Oksit & 10 & \\
\hline 900 & T.Ç. & Nikel Oksit & 10 & \\
\hline 900 & D.Ç. & Nikel Oksit & 15 & \\
\hline 900 & S.Ç. & Nikel Oksit & 15 & \\
\hline 900 & T.Ç. & Nikel Oksit & 15 & \\
\hline 900 & D.Ç. & Nikel Oksit & 20 & \\
\hline 900 & S.Ç. & Nikel Oksit & 20 & \\
\hline 900 & T.Ç. & Nikel Oksit & 20 & \\
\hline 900 & D.Ç. & Bakır Oksit & 10 & \\
\hline 900 & S.Ç. & Bakır Oksit & 10 & \\
\hline 900 & T.Ç. & Bakır Oksit & 10 & \\
\hline 900 & D.Ç. & Bakır Oksit & 15 & \\
\hline 900 & S.Ç. & Bakır Oksit & 15 & \\
\hline 900 & T.Ç. & Bakır Oksit & 15 & \\
\hline 900 & D.Ç. & Bakır Oksit & 20 & \\
\hline 900 & S.Ç. & Bakir Oksit & 20 & \\
\hline 900 & T.Ç. & Bakır Oksit & 20 & \\
\hline
\end{tabular}

\begin{tabular}{|c|c|c|c|c|}
\hline $\begin{array}{c}\text { Sicaklik } \\
\left({ }^{\circ} \mathrm{C}\right)\end{array}$ & Bünye & Katk1 & $\begin{array}{c}\text { Katk1 Oran1 } \\
(\%)\end{array}$ & Renk \\
\hline 1000 & H.M. & - & - & \\
\hline 1000 & D.Ç. & - & - & \\
\hline 1000 & S.Ç. & - & - & \\
\hline 1000 & T.Ç. & - & - & \\
\hline 1000 & D.Ç. & Kobalt Klorür & 10 & \\
\hline 1000 & S.Ç. & Kobalt Klorür & 10 & \\
\hline 1000 & T.Ç. & Kobalt Klorür & 10 & \\
\hline 1000 & D.Ç. & Kobalt Klorür & 15 & \\
\hline 1000 & S.Ç. & Kobalt Klorür & 15 & \\
\hline 1000 & T.Ç. & Kobalt Klorür & 15 & \\
\hline 1000 & D.Ç. & Kobalt Klorür & 20 & \\
\hline 1000 & S.Ç. & Kobalt Klorür & 20 & \\
\hline 1000 & T.Ç. & Kobalt Klorür & 20 & \\
\hline 1000 & D.Ç. & Nikel Oksit & 10 & \\
\hline 1000 & S.Ç. & Nikel Oksit & 10 & \\
\hline 1000 & T.Ç. & Nikel Oksit & 10 & \\
\hline 1000 & D.Ç. & Nikel Oksit & 15 & \\
\hline 1000 & S.Ç. & Nikel Oksit & 15 & \\
\hline 1000 & T.Ç. & Nikel Oksit & 15 & \\
\hline 1000 & D.Ç. & Nikel Oksit & 20 & \\
\hline 1000 & S.Ç. & Nikel Oksit & 20 & \\
\hline 1000 & T.Ç. & Nikel Oksit & 20 & \\
\hline 1000 & D.Ç. & Bakır Oksit & 10 & \\
\hline 1000 & S.Ç. & Bakır Oksit & 10 & \\
\hline 1000 & T.Ç. & Bakır Oksit & 10 & \\
\hline 1000 & D.Ç. & Bakır Oksit & 15 & \\
\hline 1000 & S.Ç. & Bakır Oksit & 15 & \\
\hline 1000 & T.Ç. & Bakır Oksit & 15 & \\
\hline 1000 & D.Ç. & Bakır Oksit & 20 & \\
\hline 1000 & S.Ç. & Bakır Oksit & 20 & \\
\hline 1000 & T.Ç. & Bakır Oksit & 20 & \\
\hline
\end{tabular}


Çizelge 2 (Devamı)

\begin{tabular}{|l|c|c|c|c|}
\hline $\begin{array}{c}\text { Sicaklik } \\
\left({ }^{\circ} \mathrm{C}\right)\end{array}$ & Bünye & Katkı & $\begin{array}{c}\text { Katkı Oranı } \\
(\%)\end{array}$ & Renk \\
\hline 1100 & H.M. & - & - & \\
\hline 1100 & D.Ç. & - & - & \\
\hline 1100 & S.Ç. & - & - & \\
\hline 1100 & T.Ç. & - & - & \\
\hline 1100 & D.Ç. & Kobalt Klorür & 10 & \\
\hline 1100 & S.Ç. & Kobalt Klorür & 10 & \\
\hline 1100 & T.Ç. & Kobalt Klorür & 10 & \\
\hline 1100 & D.Ç. & Kobalt Klorür & 15 & \\
\hline 1100 & S.Ç. & Kobalt Klorür & 15 & \\
\hline 1100 & T.Ç. & Kobalt Klorür & 15 & \\
\hline 1100 & D.Ç. & Kobalt Klorür & 20 & \\
\hline 1100 & S.Ç. & Kobalt Klorür & 20 & \\
\hline 1100 & T.Ç. & Kobalt Klorür & 20 & \\
\hline 1100 & D.Ç. & Nikel Oksit & 10 & \\
\hline 1100 & S.Ç. & Nikel Oksit & 10 & \\
\hline 1100 & T.Ç. & Nikel Oksit & 10 & \\
\hline 1100 & D.Ç. & Nikel Oksit & 15 & \\
\hline 1100 & S.Ç. & Nikel Oksit & 15 & \\
\hline 1100 & T.Ç. & Nikel Oksit & 15 & \\
\hline 1100 & D.Ç. & Nikel Oksit & 20 & \\
\hline 1100 & S.Ç. & Nikel Oksit & 20 & \\
\hline 1100 & T.Ç. & Nikel Oksit & 20 & \\
\hline 1100 & D.Ç. & Bakır Oksit & 10 & \\
\hline 1100 & S.Ç. & Bakır Oksit & 10 & \\
\hline 1100 & T.Ç. & Bakır Oksit & 10 & \\
\hline 1100 & D.Ç. & Bakır Oksit & 15 & \\
\hline 1100 & S.Ç. & Bakır Oksit & 15 & \\
\hline 1100 & T.Ç. & Bakır Oksit & 15 & \\
\hline 1100 & D.Ç. & Bakır Oksit & 20 & \\
\hline 1100 & S.Ç. & Bakır Oksit & 20 & \\
\hline 1100 & T.Ç. & Bakır Oksit & 20 & \\
\hline 1200 & H.M. & - & - & \\
\hline Ham. & & \\
\hline
\end{tabular}

H.M.: Hammaddenin kendisi, D.Ç.: Döküm çamuru, S.Ç.: Seramik çamuru, T.Ç.: Torna çamuru

\section{SONUÇLAR}

Bu çalışmada Türkiye'nin ilk açık hava müzesinde sergilenen bazaltik kayaçlardan yapılmış eserlerin özelliklerine benzer özelliklere sahip seramik bünye ve astarlar geliştirilmeye çalışılmıştır. Çalışmanın sonucunda;

Aslantaş Baraj Gölü kıyısına çökelen kil içeriği yüksek hammaddenin tane boyutunun çok küçük olması nedeniyle öğütmeye gerek kalmadan seramik bünye ve astar olarak kullanılabileceği görülmüştür.

Yapılan analizler sonucunda XRF ile yüksek $\mathrm{CaO}(\sim \% 40)$ varlığ analizinde aragonit ve kalsit formunda olduğu görülmüştür. $\quad 550-760 \quad{ }^{\circ} \mathrm{C}$ aralığında $\sim \% 22$ karbonat bozunumunun olması, üretilen seramik bünyelerde kireç patlağının oluşma riskini işaret etmektedir.

$\checkmark$ Bünyeler ve astarlar çatlaksız kurutulabilmiştir. Özellikle bünyelerin kurutulması sırasında sıcaklık uygulanması, kalıntı nemin bünyeden uzaklaştırılması, pişirimin ilk aşamasındaki çatlak oluşumunun önlenebilmesi için önemlidir.

Pişirim sonrasında bünyelerde küçülme nedeniyle çatlak oluşmamıştır. Astarlarda bünyeden ayrılma (kavlama) gözlenmemiştir.

$\checkmark$ Katkısız ve \%10, \%15, \%20 renklendirici oksit katkılı astarlar, farklı seramik çamur bünyeleri üzerinde hiçbir probleme yol açmadan $900^{\circ} \mathrm{C}$, $1000{ }^{\circ} \mathrm{C}$ ve $1100{ }^{\circ} \mathrm{C}$ sıcaklıklarda, geniş renk yelpazesine sahip, gerek estetik gerekse de teknik açıdan olumlu sonuçlar verdiği gözlenmiştir. Astarların renklendirici katkı oranlarını değiştirerek tarihi eserlerin renklerine yaklaşılabileceği düşünülmektedir.

Tarihi eserlere en yakın renkler, $800-1200{ }^{\circ} \mathrm{C}$ sıcaklık aralığında pişirilen bünyelerde elde edilmiştir. 


\section{KAYNAKLAR}

1. Karatepe-Aslantaş Açık Hava Müzesi, http://www.osmaniye.gov.tr/karatepe-muzesi, Alıntı Tarihi: 10.12.2018.

2. Badawy, I., 2004. Environmental Deterioration and Conservation of Monumental Basalt, Egypt, Ass. Univ. Bull. Environ. Res. 7(1), 153-171.

3. Grissom, C., 1990. The Deterioration and Treatment of Volcanic Stone a Review of the Literatüre Lavas and Volcans, Proceedings of the International Meeting, Easter Island Chile, 3-33.

4. Yılmaz, S., Gökbel F.M., Çakır, A., 2016. Inorganic and Organic Additives on Ceramic Bodies and Impacts on Surface, Editör: Efe Recep, Cürebal İsa, Nyussupova, Atasoy Emin, St. Kliment Ohridski University Press, ISBN: 978-954-07-4141.

5. Kilic A., Kiliç Ö., Aritan A. 2006. Duvertepe Kaolin Deposits in Balikesir (North-West Turkey) and Ceramic Properties, Asian Journal of Chemistry, 18, 1352-1360.

6. Maritan, L., Nodari, L., Mazzoli, C., Milano, A., Russo, U., 2006. Influence of Firing Conditions on Ceramic Products: Experimental Study on Clay Rich in Organic Matter, Applied Clay Science, 31(1-2), 1-15.

7. Nodari, L., Marcuz, E., Maritan L., Mazzoli, C., Russo, U., 2007. Hematite Nucleation and Growth in the Firing of Carbonate-Rich Clay for Pottery Production, Journal of the European Ceramic Society, 27(16), 4665-4673.

8. Bayer Öztürk, Z., 2017. Effect of Addition of Avanos's (Nevsehir) Clays on the Physical and Microstructure Properties of Ceramic Tile, Journal of the Australian Ceramic Society, 53(1), 101-107.

9. Molera, J., Pradell, T.. Vedrell-Saz M., 1998. The Colours of Ca-Rich Ceramic Paste: Origin and Characterization, Applied Clay Science, 13(3), 187-202.

10. Gonzalez-Garcia, F., Romero-Acosta, V., Garcia-Ramos, G., Gonzalez-Rodriguez, M., 1990. Firing Transformations of Mixtures of Clays Containing Illite, Kaolinite and Calcium Carbonate Used by Ornamental Tile Industries, Applied Clay Science, 5(4), 361-375.

11. Jord'an, M.M., Boix, A., Sanfeliu, T., de la Fuente, C., 1999. Firing Transformations of
Cretaceous Clays Used in the Manufacturing of Ceramic Tiles, Applied Clay Science, 14(4), 225234.

12. Carretero, M.I., Dondi, M., Fabbri, B., Raimondo, M., 2002. The Iinfluence of Shaping and Firing Technology on Ceramic Properties of Calcareous and Non-calcareous Illitic-Chloritic Clays, Applied Clay Science, 20(6), 301-306.

13. Bauluz, B., Mayayo, M.J., Fernandez-Nieto, C., Cultrone, G., Gonzalez Lopez, J.M., 2003. Assessment of Technological Properties of Calcareous and Noncalcareous Clays Used for the Brick-making Industry of Zaragoza (Spain), Applied Clay Science, 24(1-2), 121-126.

14. Kurama, S., Özel, E., 2009. The Influence of Different $\mathrm{CaO}$ Source in the Production of Anorthite Ceramics, Ceramics International, $35,827-830$.

15. Kiliç Ö., 2013. Impact of Physical Properties And Chemical Composition of Limestone on Decomposition Activation Energy, Asian Journal of Chemistry, 25, 8116-8120.

16. Kiliç Ö., 2013. Impact of Physical Properties And Chemical Composition of Limestone on Decomposition Activation Energy, Asian Journal of Chemistry, 25, 8116-8120.

17. Daday, M., 2015. Ekstrüzyon ile Hızlı Pişirim Terracotta Dış Cephe Kaplaması Üretiminde Süreç Parametrelerinin Araştırılması, Doktora Tezi, Anadolu Üniversitesi Fen Bilimleri Enstitüsü, Seramik Mühendisliği Anabilim Dalı.

18. Dal Bo, M., Bernardin, A.M., Hotza, D., 2014. Formulation of Ceramic Engobes with Recycled Glass Using Mixture Design, Journal of Cleaner Production, 69, 243-249.

19. Santos, G.R., Melchiades, F.G., Boschi, A.O., 2007. Development a Methodology for Monitoring the Evolution of Ripening Engobes During Burn, Cerâmica Ind., 12(5), 22-27.

20. Eren Gültekin, E., 2018. Use of Avanos (Nevsehir) Clay for Engobe Production, Journal of the Australian Ceramic Society, 54, 701-709.

21. Example of Analysis which is necessary for Ceramics Products Design, https://www. hitachi-hightech.com/file/global/pdf/products /science/appli/ana/thermal/application_TA_087 e.pdf, Alınt1 Tarihi: 11.02.2019. 